\title{
A 22-year cycle in the $F$ layer ionization of the ionosphere
}

\author{
E. Feichter, R. Leitinger \\ Institut für Meteorologie und Geophysik, Universität Graz, Halbärthgasse 1, A-8010 Graz, Austria Tel: +43 3163805257 ; \\ Fax: + 43316 384091; e-mail: leitinger@bkfung.kfunigraz.ac.at
}

\begin{abstract}
The double-sunspot-cycle variation in terrestrial magnetic activity has been well known for about 30 years. In 1990 we examined and compared the lowsolar-activity (LSA) part of two consecutive cycles and predicted from this database and from published results the existence of a double-sunspot-cycle variation in total electron content (TEC) of the ionosphere too. This is restricted to noontime when the semi-annual component is well developed. Since 1995 we have had enough data for the statistical processing for high-solar-activity (HSA) conditions of two successive solar cycles. The results confirm the LSA findings. The annual variation of TEC shows a change from an autumn maximum in cycle 21 to a spring maximum during the next solar cycle. Similar to the $a a$ indices for geomagnetic activity the TEC data show a phase change in the 1-year component of the Fourier transform of the annual variation. Additionally we found the same behaviour in the F-layer peak electron density $\left(N_{\max }\right)$ over four solar cycles. This indicates that there exists a double-sunspotcycle variation in the F-layer ionization over Europe too. It is very likely coupled with the 22-year cycle in geomagnetic activity.
\end{abstract}

\section{Introduction}

The main data source for the work on which this report is based was provided by the differential Doppler effect on the signals of the US Navy Navigation Satellites (NNSS, formerly TRANSIT, in almost polar circular orbits with a height around $1100 \mathrm{~km}$ ) (Leitinger et al., 1975; Leitinger and Putz, 1978).

Two European receiving stations have been in continuous coordinated operation since the beginning

Correspondence to: R. Leitinger of 1975: Lindau/Harz in Germany $\left(51.6^{\circ} \mathrm{N}, 10.1^{\circ} \mathrm{E}\right)$ and Graz in Austria $\left(47.1^{\circ} \mathrm{N}, 15.5^{\circ} \mathrm{E}\right)$. The evaluation results are latitudinal profiles of ionospheric electron content, which means sequences of data equidistant in latitude (data distance $0.5^{\circ}$ in geographic latitude of the $400-\mathrm{km}$ ionospheric points). Up to the mid-1980s the observations from Lindau gave more material and were used for the statistical investigation for the interval 1975-1986. The data of the station Graz were applied indirectly, namely to calibrate electron content by means of the "two-stations method" (Leitinger et al., 1975). For the high-solar-activity interval of 1988-92 the observations from Graz were used. For a given latitude there is no significant difference in monthly medians and quartiles calculated from Graz and Linda data.

For this report the electron-content values for the geographical latitudes $60^{\circ} \mathrm{N}, 55^{\circ} \mathrm{N}, 50^{\circ} \mathrm{N}$ and $45^{\circ} \mathrm{N}$ were selected. The data from Graz which reach $30^{\circ} \mathrm{N}$ show that the results are valid down to $35^{\circ} \mathrm{N}$, where the influence of the equatorial anomaly begins at HSA conditions.

The total electron content (TEC) data used for this study are monthly medians gained over 2-h intervals. The data were divided into two classes: low solar activity (LSA) $(\bar{R} \leq 40$; nominal monthly mean sunspot number for modelling purposes: $\bar{R}=20$ ) and high solar activity (HSA) $[130 \leq \bar{R} \leq 170$ (cycle 21 ), $120 \leq \bar{R} \leq 180$ (cycle 22 ), respectively, nominal value $\bar{R}=150]$. (The widening of the $\bar{R}$ interval for $\mathrm{HSA} /$ cycle 22 was necessary in order to ensure data from at least 2 years for each month. Using data according to the criterion $130 \leq$ $R_{12} \leq 170 \quad$ - all months from November 1988 to December 1991 - leads to nearly identical results in statistical investigations.)

The amount of TEC data from intermediate levels of solar activity (MSA) is not sufficient to make clear statements about the ionization behaviour under these conditions. The results of investigations of peak electron density $\left(N_{\max }\right)$ show that there is no substantial difference between the annual variation for MSA and HSA.

These selection criteria enabled us to include all data from the years 1975 and 1976 and the data from July 
Table 1. Monthly mean sunspot numbers $\bar{R}$ for the solar maximum period 1978-1982 [<: $\bar{R}<130$ (not selected), $>: \bar{R}>170$ (not selected), $x$ : no data available]

HSA (solar cycle 21)

\begin{tabular}{|c|c|c|c|c|c|c|c|c|c|c|c|c|}
\hline & $\mathbf{J}$ & $\mathrm{F}$ & $\mathrm{M}$ & A & M & $\mathbf{J}$ & $\mathbf{J}$ & A & $\mathrm{S}$ & $\mathrm{O}$ & $\mathrm{N}$ & $\mathrm{D}$ \\
\hline 1978 & $<$ & $<$ & $<$ & $<$ & $<$ & $<$ & $<$ & $<$ & 138 & $<$ & $<$ & $<$ \\
\hline 1979 & 167 & 138 & 138 & $<$ & 134 & 150 & 159 & 142 & $>$ & $>$ & $>$ & $>$ \\
\hline 1980 & 160 & 155 & $<$ & 164 & $>$ & $\mathrm{x}$ & 136 & 135 & $\mathrm{x}$ & 165 & 148 & $>$ \\
\hline 1981 & $<$ & $\mathrm{x}$ & $\mathrm{x}$ & 156 & $<$ & $<$ & 144 & 159 & 167 & 162 & 138 & 150 \\
\hline 1982 & $<$ & 164 & 154 & $<$ & $<$ & $<$ & $<$ & $<$ & $<$ & $<$ & $<$ & $<$ \\
\hline
\end{tabular}

Table 2. Monthly mean sunspot numbers $\bar{R}$ for the cycle-22 solar maximum period 1988-1992 [<: $\bar{R}<120$ (not selected), $>: \bar{R}>180$ (not selected)]

HSA (solar cycle 22)

\begin{tabular}{lllllllllllll}
\cline { 2 - 8 } & J & F & M & A & M & J & J & A & S & O & N & D \\
\hline 1988 & $<$ & $<$ & $<$ & $<$ & $<$ & $<$ & $<$ & $<$ & 120 & 125 & 125 & 179 \\
1989 & 161 & 165 & 131 & 131 & 139 & $>$ & 127 & 169 & 177 & 159 & 173 & 166 \\
1990 & 177 & 131 & 140 & 140 & 132 & $<$ & 149 & $>$ & 125 & 146 & 131 & 130 \\
1991 & 137 & 168 & 142 & 140 & 121 & 170 & 174 & 176 & 125 & 144 & $<$ & 141 \\
1992 & 150 & 161 & $<$ & $<$ & $<$ & $<$ & $<$ & $<$ & $<$ & $<$ & $<$ & $<$ \\
\hline
\end{tabular}

1984 to December 1986 into the LSA class and data from 1978-1982 selected according to Table 1 and from 1988-1992 selected according to Table 2 into the HSA class. The comparatively large variation in HSA- $\bar{R}$ might be a problem, especially when seasonal differences are to be investigated. The month-to-month differences in $\bar{R}$ are cancelled out at least partially in averages: the cycle 21 vernal average (March 1979, 1982; April 1980, 1981) is $\bar{R}=153$, the autumnal one (September, 1978, 1981; October 1980 , 1981) $\bar{R}=158$; the cycle-22 vernal average (March and April 1989, 1990, 1991) is $\bar{R}=137$, the autumnal one (September and October 1988, 1989, $1990,1991) \bar{R}=140$. Both for monthly medians of TEC and of $N_{\max }$ (or foF2) one finds considerable differences comparing data gained under comparable seasonal and solar activity $\left(\bar{R}, R_{12}\right.$ or any other solar index) conditions. Therefore some averaging is necessary. In the TEC case this was done by selecting the observed data into $(12 \times 9$, cycle- 21 , or $12 \times 12$ months, cycle 22$)$ classes (the 12 months of the year and 9 or 12 LT intervals). Medians were calculated for each data class.

The first statistical studies (see Feichter et al., 1988, 1990, 1991; Feichter and Leitinger, 1993) could be based on two LSA intervals (1975-1976 and 1984-1986) (Fig. 1) and on the cycle-21 HSA interval (1978-1982). In 1989 we investigated data of 1984-1986 to be able to compare two consecutive solar minima (1975-1976 and 1984-1986) (Feichter et al., 1990). Since 1995 we have had enough data to compare the HSA period of cycle 22 (selected months 1988 to 1992, see Table 2) with that of cycle 21 too.

To extend the investigation to a wider range of solar cycles we obtained the annual variation of $N_{\max }$ with ionosonde scalings (hourly values of foF 2 ) from several ionosonde stations (Table 3). For $N_{\max }$ linear regressions
Table 3. Data sources for the figures with F-layer ionization examples

\begin{tabular}{llll}
\hline $\begin{array}{l}\text { solar } \\
\text { cycle }\end{array}$ & years & data and sources & method \\
\hline 19 & $1958-1964$ & $N_{\max }$, European ionosondes & regression \\
20 & $1969-1974$ & $N_{\max }$, European ionosondes & regression \\
20 & 1968 & Faraday-TEC, Stanford & 1 -year \\
21 & $1976-1980$ & $N_{\max }$, European ionosondes & regression \\
21 & $1980-1985$ & $N_{\max }$, European ionosondes & regression \\
21 & $1975-1976$ & NNSS-TEC, Lindau-Graz & selected months \\
21 & $1978-1982$ & NNSS-TEC, Lindau-Graz & selected months \\
22 & $1984-1986$ & NNSS-TEC, Lindau-Graz & selected months \\
22 & $1988-1991$ & NNSS-TEC, Graz-Lindau & selected months \\
\hline
\end{tabular}

were applied to find the relation between solar activity $\left(R_{12}\right)$ and peak electron density for each month and for each hour of the day. From the linear regression relation $N_{\max }$ was calculated for a selected level of solar activity. The regressions were based on different data selections, e.g. all data of one solar cycle, data from the rising part of a cycle and data from the falling part, the interval around the solar maximum. Some regressions failed and gave negative slopes and/or negative $R_{12}=0$ interception points. However, no failures occurred during daytime. For HSA $\left(R_{12}=150\right)$ and intermediate levels of solar activity (e.g. $R_{12}=85$ ) the 22 -year periodicity is stable and does not depend on the data selection for the regressions: it appears when all data of one cycle are included, and in partial data (rising part, falling part, etc.). The examples used in this report show HSA $\left(R_{12}=150\right)$ cases of one ionosonde station, Rome, Italy $\left(41.8^{\circ} \mathrm{N}, 12.5^{\circ} \mathrm{E}\right)$.

An additional remark: attempts to find a solar-cycle dependence in tropospheric dynamics ("weather") have been based on the cycle-to-cycle differences of the semiannual component of magnetic activity (Baranyi and Ludmány, 1992, 1995a, 1995b). An influence on the ionosphere is much more likely than an influence on the troposphere

\section{Data Analysis}

The results are discussed in terms of the Fourier transform of the twelve monthly medians of the annual variation (cosine terms $a_{0} \cdots a_{6}$, sine terms $b_{1} \cdots b_{5}$ ) and reconstruction to order $n$ :

$$
\begin{aligned}
F_{n}(t)= & \sum_{j=0}^{n} a_{j} \cos (j \omega t)+\sum_{j=1}^{n} b_{j} \sin (j \omega t) \\
= & a_{0}+a_{1} \cos (\omega t)+b_{1} \sin (\omega t)+a_{2} \cos (2 \omega t) \\
& +b_{2} \sin \left(2 \omega_{t}\right)+\cdots \\
= & C_{0}+C_{1} \cos \left(\omega t-\phi_{1}\right)+C_{2} \cos \left(2 \omega t-\phi_{2}\right)+\cdots
\end{aligned}
$$

with $C_{j}=\sqrt{a_{j}^{2}+b_{j}^{2}}$ and $\tan \phi_{j}=\frac{b_{j}}{a_{j}}$.

$\omega=\frac{2 \pi}{12}(t$ in months $)$ or $\omega=\frac{2 \pi}{365.25}$ ( $t$ in days $)$ 
The Fourier decomposition gives the possibility to study asymmetries in the annual variation by means of the relation of the 1-year component to the 1/2-year component.

\subsection{Behaviour of the amplitudes}

The average values $\left(C_{0}=a_{0}\right)$ increase with decreasing latitude. From solar cycle to solar cycle the change in value of the maximum of the average is less than $10 \%$. The general level of ionization (averaged over 1 year) shows nearly no changes from solar cycle to solar cycle.

A minimal value of the annual component $\left(C_{1}=\right.$ $\left.\sqrt{a_{1}^{2}+b_{1}^{2}}\right)$ appears around noon, therefore the semiannual component has a strong influence for this timeinterval. For cycle 21, LSA, the positions of the absolute maximum of the semi-annual component $\left(C_{2}=\right.$ $\sqrt{a_{2}^{2}+b_{2}^{2}}$ ) and the noon minimum of the annual component coincide. For cycle 22, LSA, the annual component predominates during the whole day, except in the interval 1100-1300 LT. For HSA, predominance of the annual component over the semi-annual one exists only during night-time (Fig. 2, top). This is the reason why the annual variation shows distinct peaks during daytime. The annual variation has a well-defined semi-annual character (cf. Fig. 3) and the difference between vernal and autumnal maximum is more pronounced than during LSA.

For HSA of cycle 22 the semi-annual amplitude reaches the maximum very late (1700-1900 LT), and therefore the semi-annual component is still visible in the annual variation up to midnight (Fig. 2). The vernal maximum shows up until 2200 LT, contrary to the cycle21 case.
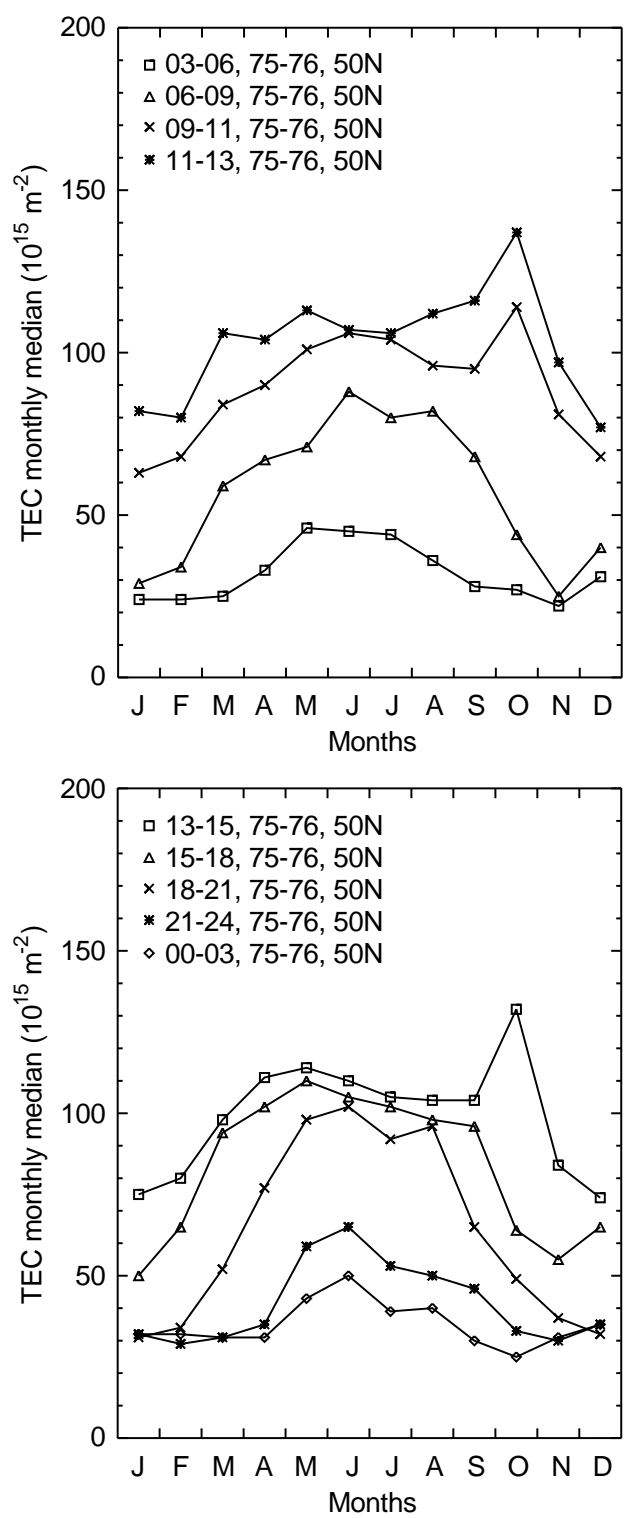
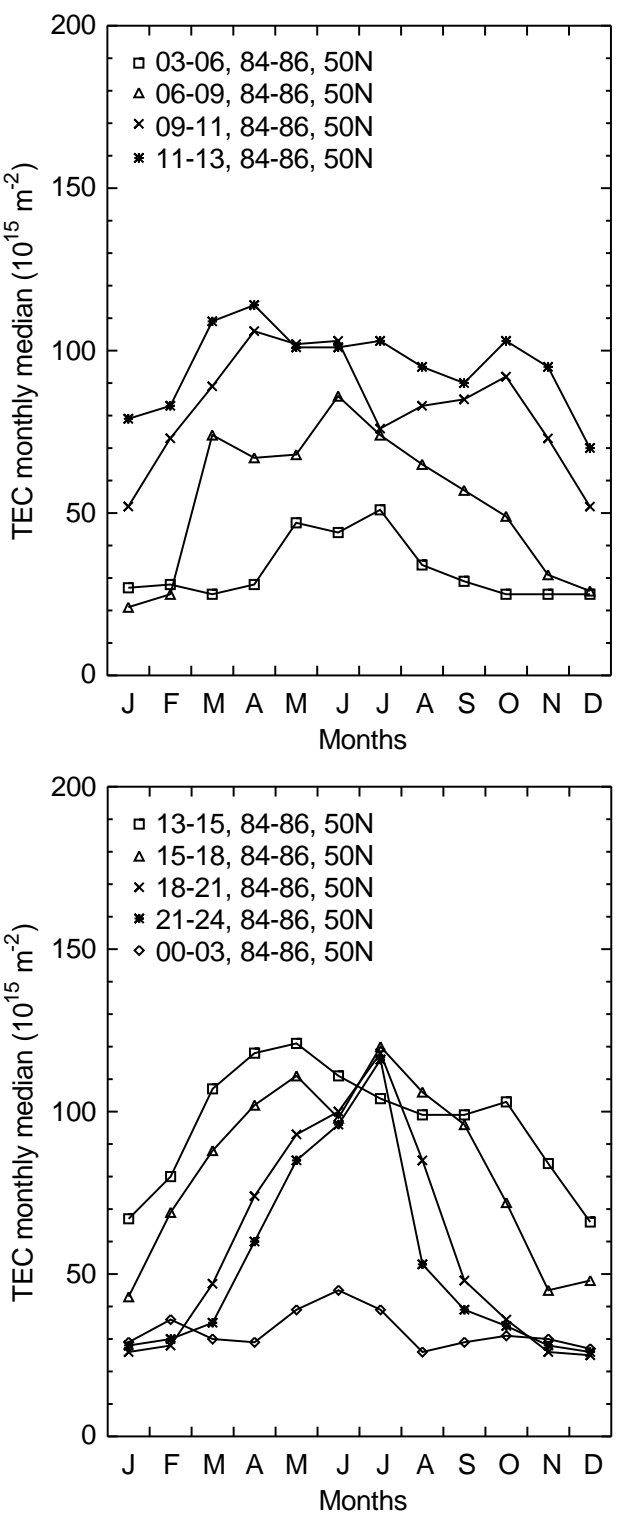

Fig. 1. Annual variation of monthly medians of ionospheric electron content for $50^{\circ} \mathrm{N}$ for intervals. LSA cycle 21 (left) and cycle 22 (right). From Feichter et al., (1990). 


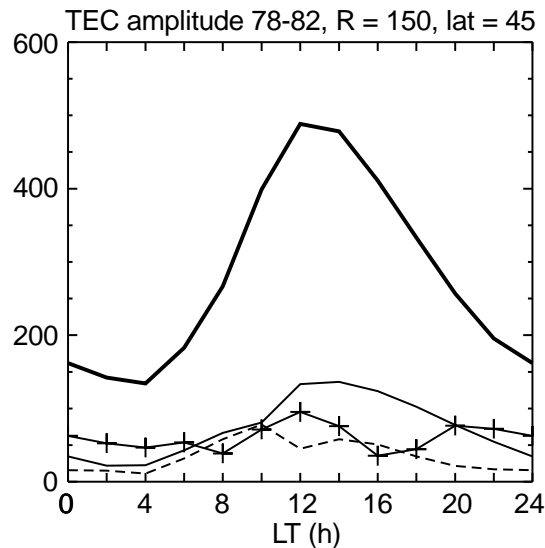

TEC phase (deg.) $78-82, R=150$, lat $=45$
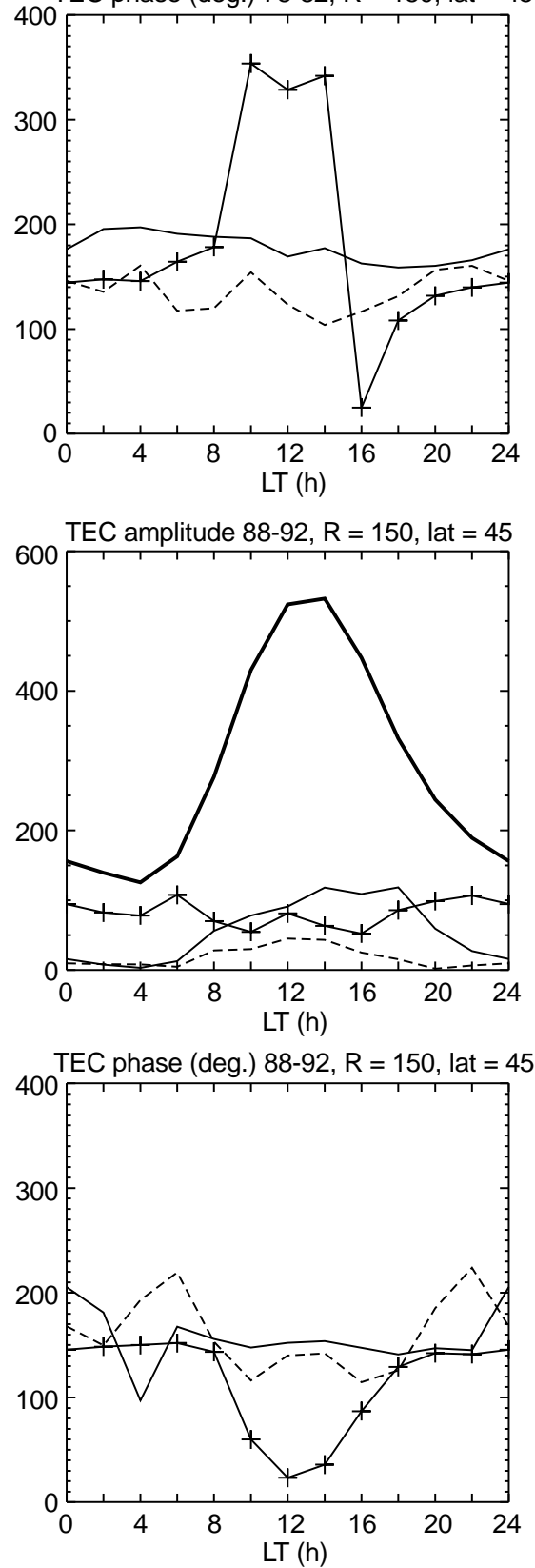

TEC amplitude 78-82, $R=150$, lat $=50$

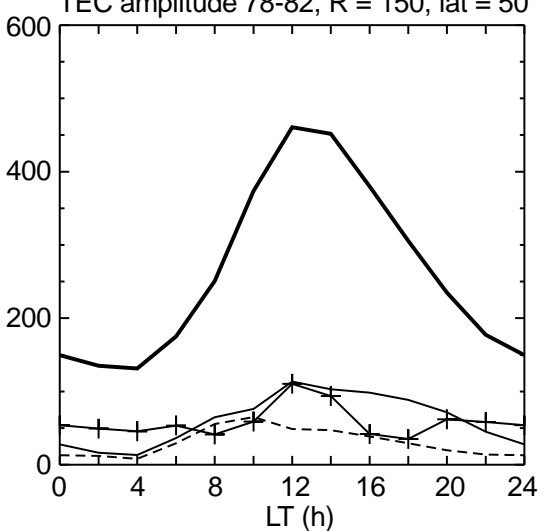

TEC phase (deg.) $78-82, R=150$, lat $=50$

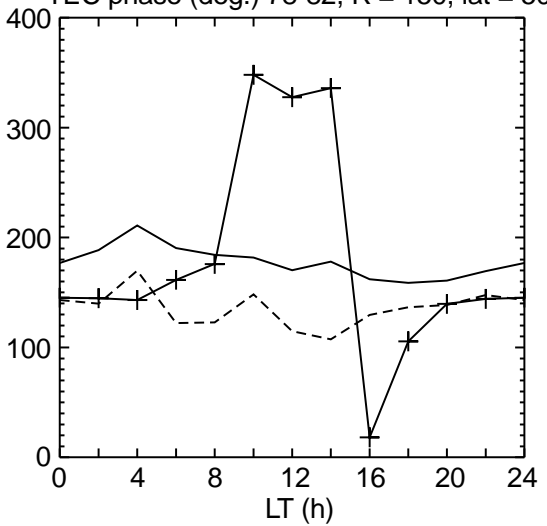

TEC amplitude 88-92, $R=150$, lat $=50$

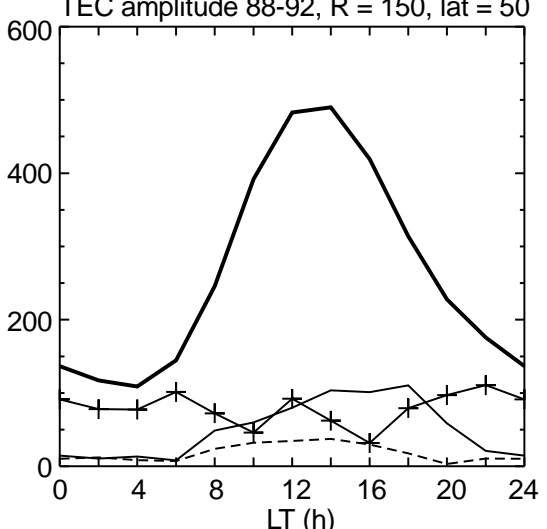

TEC phase (deg.) 88-92, $R=150$, lat $=50$

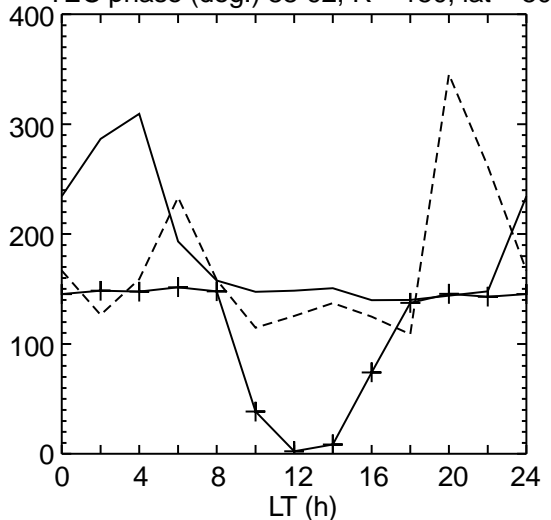

TEC amplitude $78-82, R=150$, lat $=55$

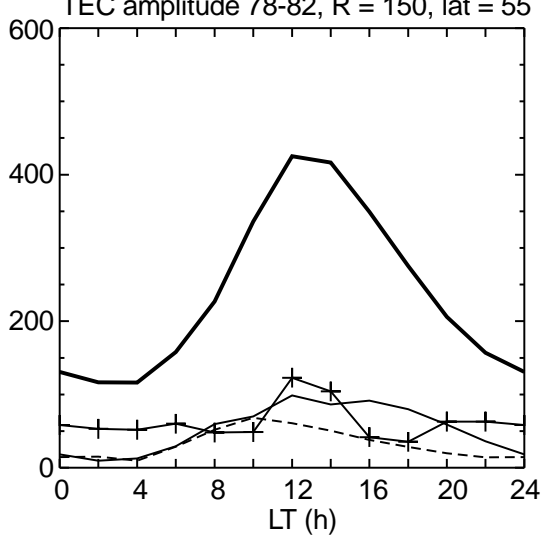

TEC phase (deg.) $78-82, R=150$, lat $=55$

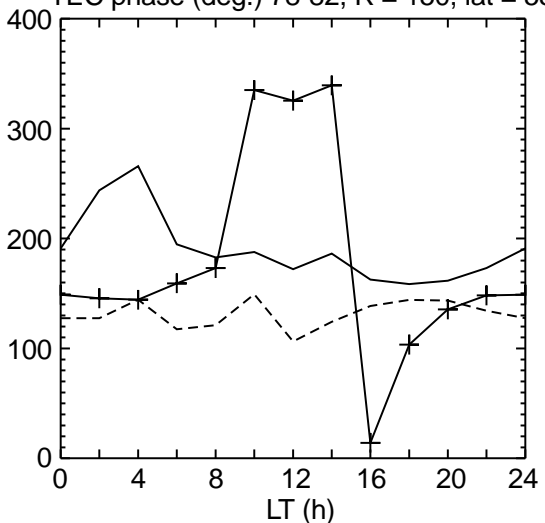

TEC amplitude $88-92, R=150$, lat $=55$

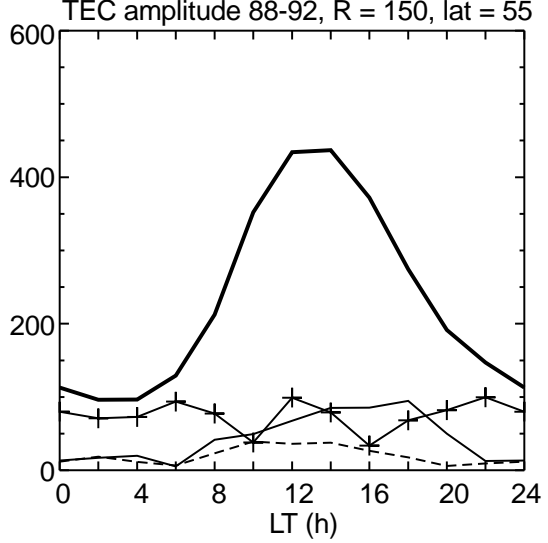

TEC phase (deg.) $88-92, R=150$, lat $=55$

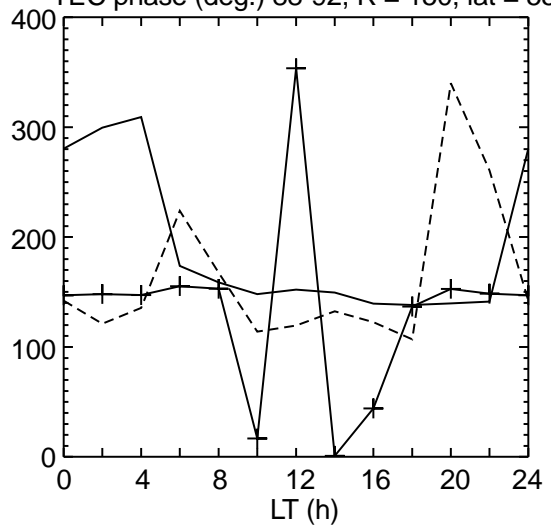

Fig. 2. Diurnal variation of amplitudes (top and third row) and phases (second and bottom row) for Fourier components of the annual variation of ionospheric electron content (TEC): mean (heavy lines), 1year (crosses), 1/2 year (thin line), 4-months (dashed line). High solar activity $(\bar{R}=150)$. Solar cycles 21 (top) and 22 (bottom). LT from 00 to $24 \mathrm{~h}$. Geographic latitude $45^{\circ} \mathrm{N}$ (left-hand panels), $50^{\circ} \mathrm{N}$ (middle panels) and $55^{\circ} \mathrm{N}$ (right-hand panels); based on bi-hourly monthly medians from months selected according to the solar-activity criterion 

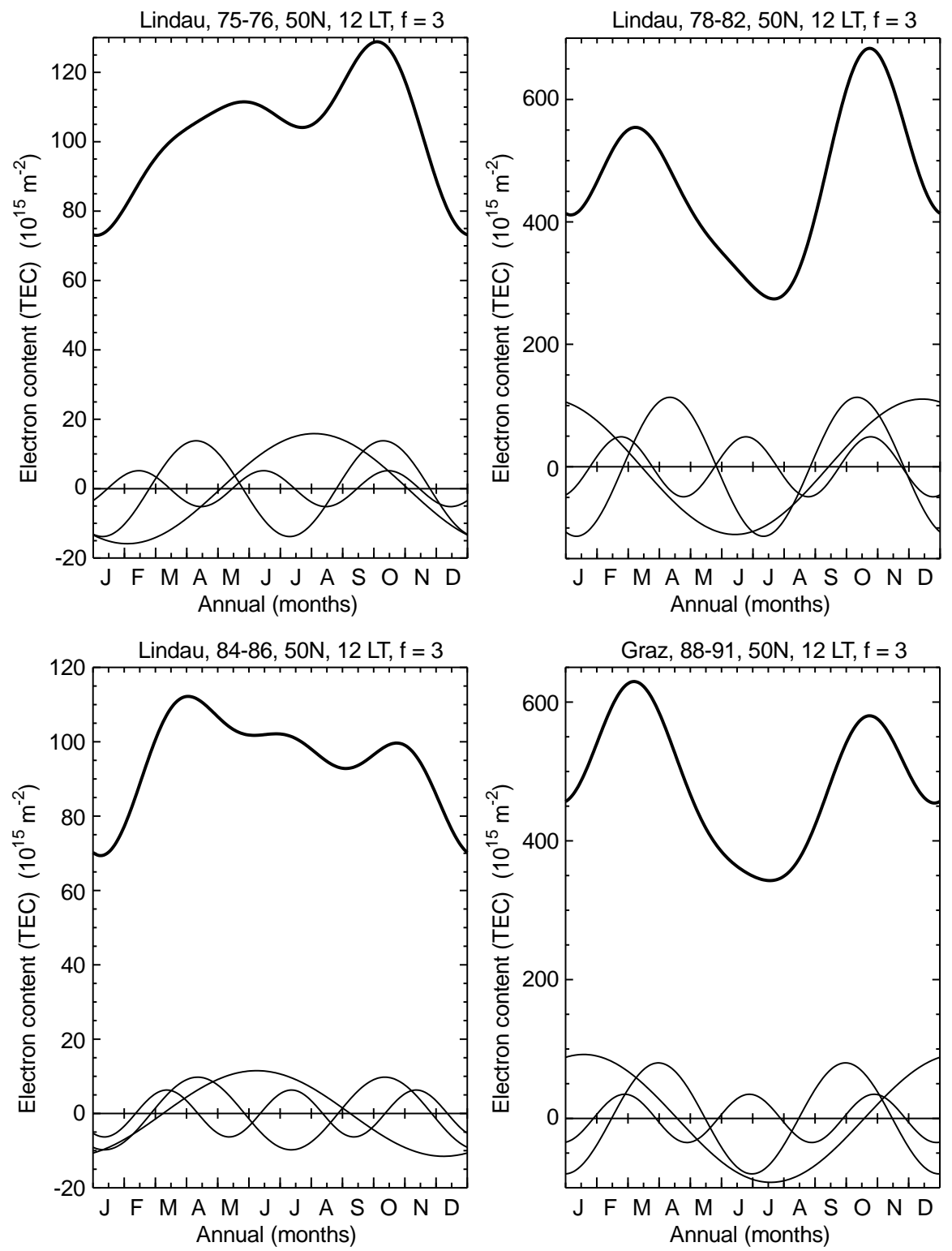

Fig. 3. Annual variation of ionospheric electron content (TEC) from four Fourier components (mean, 1-year, 1/2-year, 4-months). Low solar activity $(\bar{R}=20)$ left-hand side, high solar activity $(\bar{R}=150)$ right hand-side; solar cycles 21 (top) and 22 (bottom). The 1 year, 1/2-year, 4-months components are shown separately (thin lines); based on bi-hourly monthly medians from months selected according to the solar activity criterion

\subsection{Behaviour of the phases}

\subsubsection{Annual component}

For cycle 21 for LSA the maximum of the annual component appears during summer (from 1500 to 0900 LT during the second half of June) (Table 4). For the other daytime intervals we find the maximal values between the first half of July and the first half of August (different from the following cycle). Higher latitudes show the same results. The high winter night values are caused by the strong semi-annual component with maxima in June and December.

For HSA there is a change in phase from day to night. From 1900 to 0900 LT the maximum of the annual component occurs in the first half of June and from 0900 to $1700 \mathrm{LT}$ between the first half of December and the second half of February (Table 4, Fig. 2, top). The interval $1700-1900$ LT is a transition between night- and daytime behaviour (Table 4). During
1978-1982 the phase of the annual component shows a clear leap from night to day but a smoother one from day to night. All latitudes give the same results.

During cycle 22 (LSA) the maximum of the annual component also appears during summer; from 1500 to 0900 LT during the second half of June (same result in cycle 21). For the other daytime intervals we find the location of the maximal values in the first half of June: one or two months earlier than in the previous cycle (Table 4). Higher latitudes show the same results. The annual variation is comparatively flat around noon because the 4 month component has a maximum in summer (between the maxima of the semi-annual component).

For HSA there is a change in phase from day to night. From 1900 to 0900 LT the maximum of the annual component occurs in the first half of June (like cycle 21) but from 0900 to 1700 LT between the second half of January and March: one or two months later than in the previous cycle (Fig. 3, Table 4). The interval 
Table 4. Occurence of the maxima of the annual and semi-annual Fourier components of TEC for solar cycles 21 and 22

Cycle 21. 1978-1982 (HSA: $\bar{R}=150$ ), geogr. latitude $50^{\circ} \mathrm{N}$

\begin{tabular}{lll}
\hline LT interval & $\begin{array}{l}\text { maximum of the } \\
\text { annual component }\end{array}$ & $\begin{array}{l}\text { maximum of the } \\
\text { semi-annual compo }\end{array}$ \\
\hline $23-1$ & first half of June & first half of April \\
second half of Aprill \\
first half of June & first half of June & second half of Apri \\
$3-5$ & second half of June & second half of April \\
$5-7$ & first half of July & second half of April \\
$7-9$ & first half of January & second half of Apri \\
$9-11$ & first half of December & first half of April \\
$11-13$ & second half of December & first half of April \\
$13-15$ & second half of February & first half of April \\
$15-17$ & first half of May & first half of April \\
$17-19$ & first half of June & first half of April \\
$19-21$ & first half of June & first half of April \\
$21-23$ & tatits
\end{tabular}

Cycle 22. 1988-1991 (HSA: $\bar{R}=150)$, geogr. latitude $50^{\circ} \mathrm{N}$

\begin{tabular}{lll}
\hline LT interval & $\begin{array}{l}\text { maximum of the } \\
\text { annual component }\end{array}$ & $\begin{array}{l}\text { Maximum of the } \\
\text { semi-annual component }\end{array}$ \\
\hline $23-1$ & first half of June & $\begin{array}{l}\text { second half of April } \\
\text { first half of June }\end{array}$ \\
$1-3$ & first half of June & second half of June \\
$3-5$ & first half of April \\
$5-7$ & second half of June & first half of June \\
$7-9$ & second half of February & spril \\
$9-11$ & second half of January & second half of March \\
$11-13$ & second half of January & first half of April \\
$13-15$ & second half of March \\
$15-17$ & second half of May & second half of March \\
$17-19$ & first half of June & second half of March \\
$19-21$ & first half of June & second half of March \\
$21-23$ & second half of March
\end{tabular}

Cycle 21. 1975-1976 (LSA: $\bar{R}=20$ ), geogr. latitude $50^{\circ} \mathrm{N}$

\begin{tabular}{|c|c|c|}
\hline LT interval & $\begin{array}{l}\text { maximum of the } \\
\text { annual component }\end{array}$ & $\begin{array}{l}\text { Maximum of the } \\
\text { semi-annual component }\end{array}$ \\
\hline $\begin{array}{l}23-1 \\
1-3 \\
3-5 \\
5-7 \\
7-9 \\
9-11 \\
11-13 \\
13-15 \\
15-17 \\
17-19 \\
19-21 \\
21-23\end{array}$ & $\begin{array}{l}\text { second half of June } \\
\text { first half of June } \\
\text { second half of June } \\
\text { second half of June } \\
\text { second half of June } \\
\text { second half of July } \\
\text { first half of August } \\
\text { first half of July } \\
\text { second half of June } \\
\text { second half of June } \\
\text { second half of June } \\
\text { first half of July }\end{array}$ & $\begin{array}{l}\text { second half of June } \\
\text { second half of June } \\
\text { second half of June } \\
\text { first half of July } \\
\text { first half of March } \\
\text { second half of April } \\
\text { first half of April } \\
\text { first half of April } \\
\text { first half of April } \\
\text { second half of April } \\
\text { first half of June } \\
\text { second half of June }\end{array}$ \\
\hline \multicolumn{3}{|c|}{ Cycle 22. 1984-1986 (LSA: $\bar{R}=20$ ), geogr. latitude $50^{\circ} \mathrm{N}$} \\
\hline LT interval & $\begin{array}{l}\text { maximum of the } \\
\text { annual component }\end{array}$ & $\begin{array}{l}\text { maximum of the } \\
\text { semi-annual component }\end{array}$ \\
\hline $\begin{array}{l}23-1 \\
1-3 \\
3-5 \\
5-7 \\
7-9 \\
9-11 \\
11-13 \\
13-15 \\
15-17 \\
17-19 \\
19-21 \\
21-23\end{array}$ & $\begin{array}{l}\text { second half of June } \\
\text { first half of June } \\
\text { second half of June } \\
\text { second half of June } \\
\text { second half of June } \\
\text { first half of June } \\
\text { first half of June } \\
\text { first half of June } \\
\text { second half of June } \\
\text { second half of June } \\
\text { second half of June } \\
\text { second half of June }\end{array}$ & $\begin{array}{l}\text { second half of June } \\
\text { second half of June } \\
\text { second half of June } \\
\text { second half of May } \\
\text { first half of April } \\
\text { second half of April } \\
\text { first half of April } \\
\text { first half of April } \\
\text { second half of March } \\
\text { first half of February } \\
\text { second half of June } \\
\text { second half of June }\end{array}$ \\
\hline
\end{tabular}


1700 to 1900 LT is a transition between night- and daytime behaviour too (Table 4, Fig. 2, bottom). The change of phase of the annual component is smoother than in cycle 21 and the change occurs earlier for $60^{\circ} \mathrm{N}$ than for $50^{\circ} \mathrm{N}$.

\subsubsection{Semi-annual component}

For cycle 21 for LSA the maximum of the semi-annual part shows a different position for day and night. At night it occurs around the solstices (1900 to $0700 \mathrm{LT}$, second half of June), and during the day around the equinoxes (April, October). During the interval 0500 0700 LT there is a night-to-day change (Table 4).

During the time of HSA the phase of the semi-annual component is very stable (April, October) (Table 4). Only for high latitudes for 0100-0500 LT does the phase change to May $\left(55^{\circ} \mathrm{N}\right)$ and June $\left(60^{\circ} \mathrm{N}\right)$. The development of the "visibility" of the autumn maximum occurs later (10 a.m.) than in the following cycle, and disappears earlier (Figs. 2 and 4, top).

For cycle 22 for LSA the maximum of the semiannual part shows almost the same behaviour as during the previous cycle (Table 4). The change from day to night behaviour is more distinct (1700-1900 LT, February).

During the time of HSA the phase of the semi-annual component is very stable too, but in daytime it occurs during this cycle half a month earlier (second half of March, first half of April) (Table 4 and Figs. 2 and 5, bottom). Only for latitudes from 50 to $60^{\circ} \mathrm{N}$ does the phase change from 0100 to $0500 \mathrm{LT}$ to June (Table 4).

\subsubsection{4-month component.}

During HSA the 4-month component also visibly influences the annual variation. Cycle 21: the maxima occur at the end of October, February and June and intensify the autumn maximum with the annual variation. Cycle 22: the maxima occur at the begin of March, July and November and strengthen the spring maximum of the annual variation.

\section{Long-term behaviour of geomagnetic activity}

The long-term behaviour of geomagnetic activity follows roughly the solar activity. However, marked differences were already found at the beginning of this century (e.g. Cortie, 1912). The maximum of geomagnetic activity is delayed when compared with the maximum of solar activity. Geomagnetic activity has a pronounced annual variation (dominant semi-annual component) whereas solar activity has none (FraserSmith, 1972). Refined studies revealed that the annual variation of geomagnetic activity is not due to an influence of the atmosphere-ionosphere-magnetosphere system of the earth but is an effect of the earth-sun geometry (compare, e.g. Russell and McPherron, 1973, Triskova, 1989). For the development of the semi- annual variation there exist two theories: the axial hypothesis (Priester and Cattani, 1962) and the equinoctial hypothesis (Bartels, 1963), which has been used for ionospheric investigations (e.g. Apostolov and Alberca, 1995).

\subsection{Vernal-autumnal asymmetry in the seasonal variation of geomagnetic activity}

A double-sunspot-cycle variation also occurs in terrestrial magnetic activity (Chernosky, 1966). Chernosky found that in even-numbered cycles the last half of the sunspot-number cycle is more active than the first half, and the converse is true for the odd-numbered cycles. The curve of the 22-year cycle of magnetic activity is not symmetric to the minimum between two cycles. Münch (1972) found an annual wave in the odd-numbered sunspot cycles and explained its generation by an asymmetry in sunspot activity in the two solar hemispheres and by the inclination of the sun's equator with respect to the ecliptic. Meyer (1972) investigated C8 character figures and found two annual waves to exist in antiphase, with maxima around the equinoxes.

In 1988 the vernal-autumnal asymmetry in the seasonal variation of geomagnetic activity was investigated by L. Truisková. In investigating the variation of geomagnetic activity, not from the viewpoint of solar cycles but with respect to the polarity of the main solar dipole, an annual wave can be observed with maxima alternatively in the periods of vernal and autumnal equinoxes. The phenomenon could be explained by the asymmetry in the main solar dipole field and the result is a stronger influence of the dominant polarity in one of the solar hemispheres. It enhances or attenuates one of the maxima of geomagnetic activity. After 1913 the dominant polarity of the southern solar hemisphere had a greater influence which, under negative polarity (e.g. 1972-1980) enhances, and under positive polarity (e.g. 1960-1969, 1982-1987) attenuates the vernal geomagnetic activity maximum in comparison with the autumnal one (Triskova, 1989).

\subsection{The influence of magnetic activity on mid-latitude F-layer ionization}

Assuming that a suitable geomagnetic index is an indicator for particle precipitation in higher latitudes, the (statistical) effect of the annual variation of geomagnetic activity on the annual variation of F-layer ionization could be based on the Joule heating effect of energetic particles reaching E- and D-layer heights. A widely accepted theory for F-layer "negative storm effects" (e.g. Taeusch et al., 1971; Prölss, 1987; Prölss and Roemer, 1987) assumes changes of the thermospheric wind system and changes of thermospheric neutral gas composition. The wind change depresses F-layer ionization in mid-latitudes because the plasma is pushed to lower altitudes, which results in increased recombination. The composition change decreases the 

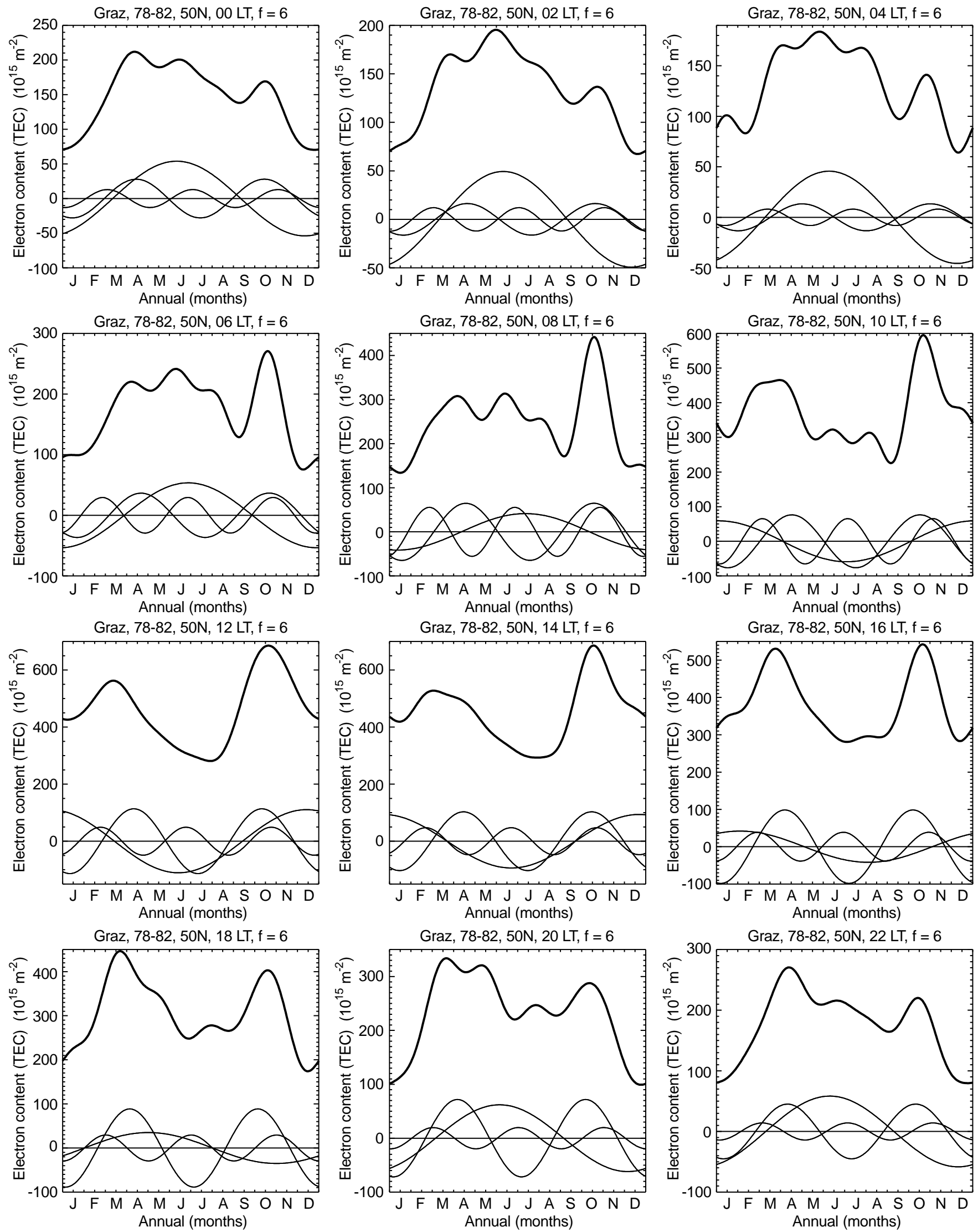

Fig. 4. Annual variation of ionospheric electron content (TEC) for $50^{\circ} \mathrm{N}$ from all 6 Fourier components (mean, 1 year, $\cdots, 2$ months) (Fourier interpolation). The original monthly medians are the TEC values in the middle of each monthly interval. High solar activity
$(\bar{R}=150)$, solar cycle $21, \mathrm{LT}$ from 00 to $22 \mathrm{~h}$. The first four Fourier components are shown. Based on bi-hourly monthly medians from months selected according to the solar activity criterion 

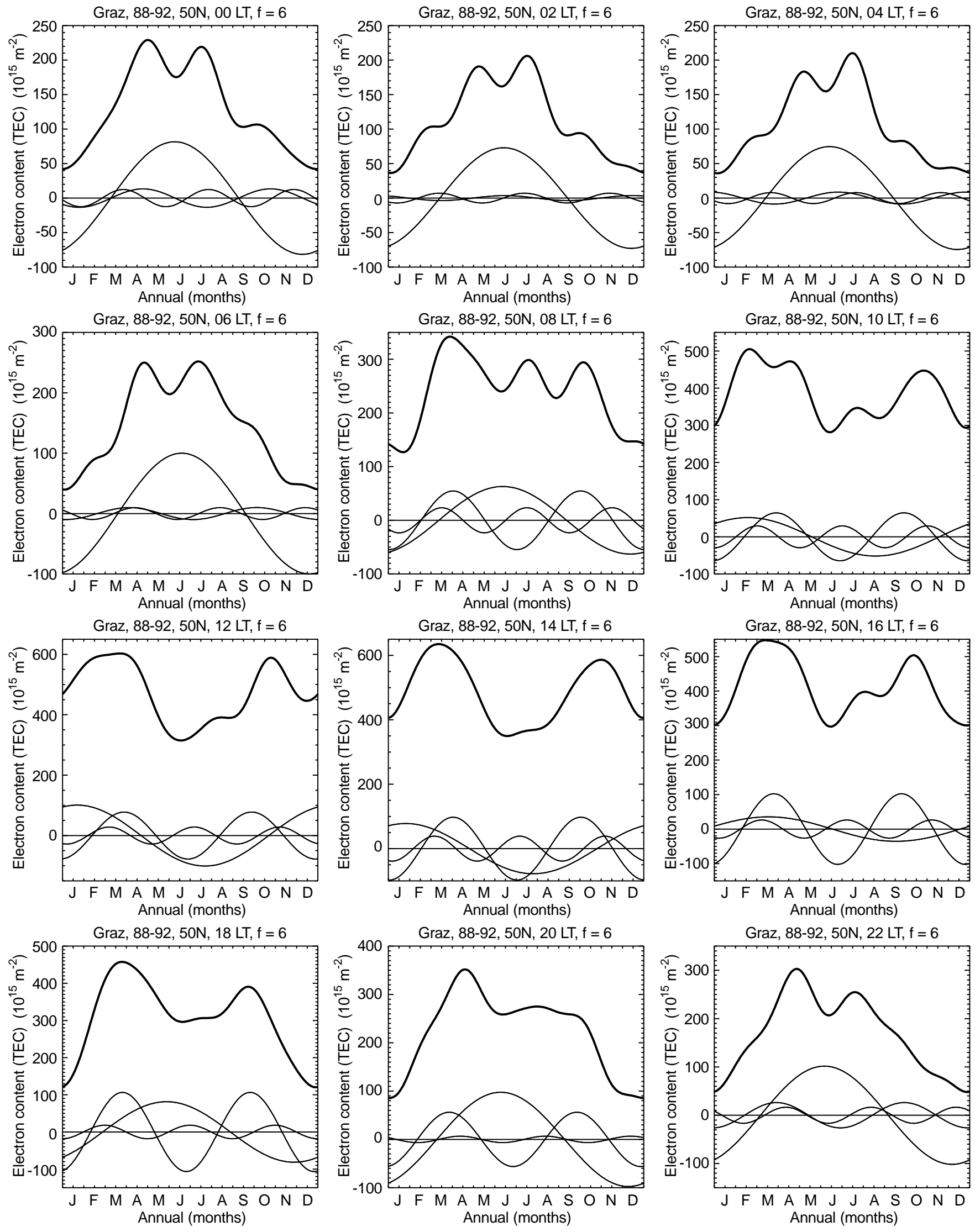

Fig. 5. As for Fig. 4 but for solar cycle 22 
number density ratio $[0] /[\mathrm{N} 2]$, which also leads to a depression of ionization because recombination is enhanced as compared with production. The "negative storm effect" is a typical phenomenon which is observed on the day following the day of the onset of a geomagnetic storm. In general it is observed in connection with moderate and severe geomagnetic storms. Usually the mid-latitude F-layer reaction to weak storms and to substorms is not directly observable because weak effects are masked by ionization variations not related to geomagnetic activity (day-to-day variability, TIDs, etc.). Experience with a large amount of European data (electron content, peak density) shows that "positive storm effects", which can occur in the afternoon when the onset of the geomagnetic storm is in the (early) morning, do not cancel out the "negative effects". We have reason to believe that the statistical effect of geomagnetic disturbances on F-layer ionization in (European) mid-latitudes is a depression of ionization. Therefore the annual asymmetry of F-layer ionization in mid-latitudes should be in anti-phase with the vernal-autumnal asymmetry of geomagnetic activity. This is what we have observed.

The dominance of negative storm effects in summer was shown by Putz et al. (1990) for three European stations. At Stanford, USA $\left(35^{\circ} \mathrm{N}\right)$, in summer, the negative effects were much larger than the positive ones (Titheridge and Buonsanto, 1988). Only in winter can positive effects dominate (Putz et al., 1990; Titheridge and Buonsanto, 1988). Since no reports on statistical studies of equinoctial storms were found, we made an investigation of the effect of geomagnetic disturbances in the following way. Long series of the quantity $\Delta=\left(N_{\max }-\overline{N_{\max }}\right) / \overline{N_{\max }}$ were calculated for given local time and compared with the daily geomagnetic disturbance index $A_{p}\left(\overline{N_{\max }}\right.$ : monthly average). To account for the delay of ionospheric effects compared with geomagnetic effects we took the $A_{p}$ of the previous day. For each month we calculated the sum of $\Delta$ when $A_{p}$ was greater than a limit value. For the $N_{\max }$ data from Rome, Italy, from the time-interval 1958 through to 1994 we obtained, with $A_{p}$ limits between 5 and 30, very stable results: only winter sums of $\Delta$ are positive, all the others negative. No difference was found between the months around the equinoxes (March, April, September, October) and summer. The $\Delta$ sum for the whole year is strongly negative.

We do not want to rule out other possibilities to explain the double sunspot cycle observed in electron content and in peak density, but it is unlikely that a pure solar-activity explanation can be found. There is no reason to believe in seasonal changes of the relation of a solar-activity indicator to the solar EUV output.

\section{Discussion of the results}

Our investigation of two consecutive cycles (cycle 21 and 22) indicates the existence of a 22 -year period in the daytime TEC of the ionosphere. During cycle 21 the maximum of the annual variation shows a distinct autumn maximum. During cycle 22 this occurs in spring. This change is caused by a shift of the annual component with respect to the semi-annual component of one or two months during daytime. (Only during this timeinterval the semi-annual component is evident: Figs. 4 and 5.) We got the same results for LSA and HSA.

For LSA of cycle 21 the maximum of the annual component occurs later in summer and therefore supports the development of an autumn maximum. For HSA of cycle 21 the maximum slips to the first half of winter (December, January) and causes the same effect. The autumn maximum (cycle 21) and the spring maximum (cycle 22) is additionally increased by the same-season maximum of the 4-month component. The change of the time of the maximum is supported by data and descriptions published in previous publications for cycles 20 and 21 (Yuen and Roelof, 1967; da Rosa et al., 1973; Huang, 1979). The paper by Garriott et al. (1970) displays electron content from the Faraday effect on the signals of ATS-1. The data from 1968 show a clear spring maximum both for Stanford $\left(34.2^{\circ} \mathrm{N}, 234.5^{\circ} \mathrm{E}\right)$ and Hawaii $\left(19.8^{\circ} \mathrm{N}, 202.8^{\circ} \mathrm{E}\right) .1968$ was a year with fairly uniform solar activity $\left(103 \leq R_{12} \leq 111\right)$. Our Fourier analysis for the Stanford 1968 data is shown in Fig. 6. (Compare also Titheridge et al., 1996.)

For Europe, Galdón and Alberca (1970) show a spring maximum for 1965, 1966 and 1967 (Tortosa, $40.8^{\circ} \mathrm{N}, 0.5^{\circ} \mathrm{E}$; cycle 20 ). The vernal-equinox values exceed the autumnal ones by more than a factor of 2 . We suspect an overestimation because of artificial enhancement by the normalization to a constant level of solar activity. The European data were gained by means of the Faraday effect on the $40 / 41-\mathrm{MHz}$ signals of

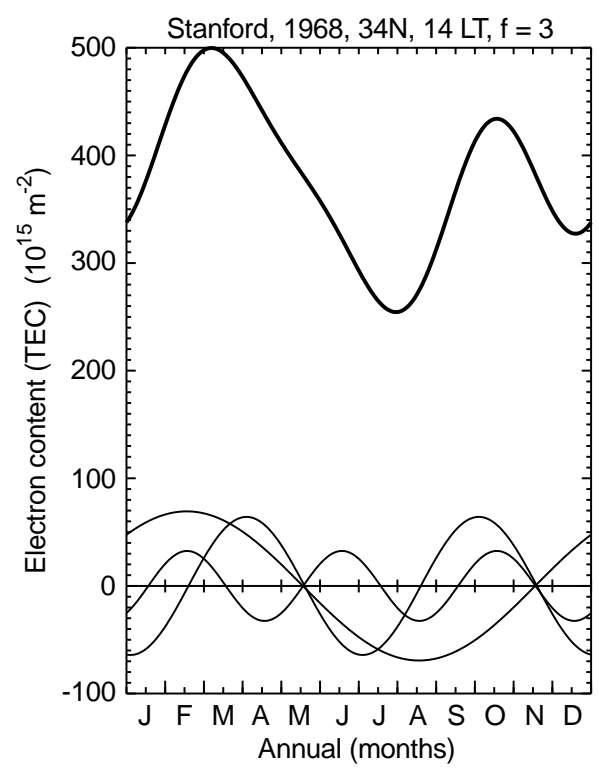

Fig. 6. Annual variation of ionospheric electron content (TEC) from four Fourier components (mean, 1 year, $1 / 2$ year, 4 months). The latter three components are shown separately (thin lines). Intermediate level of solar activity $\left(103 \leq R_{12} \leq 111\right)$, solar cycle 20 . Data from the Faraday effect on the VHF signals of the geostationary satellite ATS1, receiving station Stanford, USA. Bi-hourly monthly medians from 1968 (1 year) 
a low orbiting satellite (Explorer 22) which coupled diurnal and annual variation.

A comparison with the southern hemisphere brought no results for our investigations (Titheridge et al., 1996). There seems to be no marked difference between vernal and autumnal maximum in the southern hemisphere.

The investigation of the annual variation of peak electron density ( $N_{\max }$ : Fig. 7 ) also indicates the existence of a 22-year cycle in daytime F-layer ionization (considering data as early as solar cycle 19).

We show results for Rome $\left(41.8^{\circ} \mathrm{N}, 12.5^{\circ} \mathrm{E}-\right.$ Fig. 7) and remark that the amplitude of the 22-year periodicity gets weaker when the latitude of the ionosonde station is increased [e.g. when the results for Slough $\left(51.5^{\circ} \mathrm{N},-0.6^{\circ} \mathrm{E}\right)$ are compared with those for Rome]. This seems to correspond with a decrease in the ratio of the amplitudes of the semi-annual component com- pared with the annual component (for TEC compare Fig. 2)

No distinct and persistent double-sunspot-cycle behaviour can be found for solar activity. In particular there is no significant semi-annual component in solaractivity spectra. There is no indication of an annual variation in the relation between a solar-activity indicator (based on sunspot numbers or on solar radio flux) and the EUV output of the sun.

But, as already mentioned, the double-sunspot-cycle variation also occurs in terrestrial magnetic activity. Edwin Chernosky found an even cycle-odd cycle asymmetry in the average of "disturbed-day occurrence" from grouped data for 1884-1963 (Chernosky, 1966). Ludmila Trusková detected a very clear vernal-autumnal asymmetry in the average annual variation of the $a a$ index (see Mayaud, 1972) and a change of the maximum from spring in odd cycles to autumn in even cycles. This
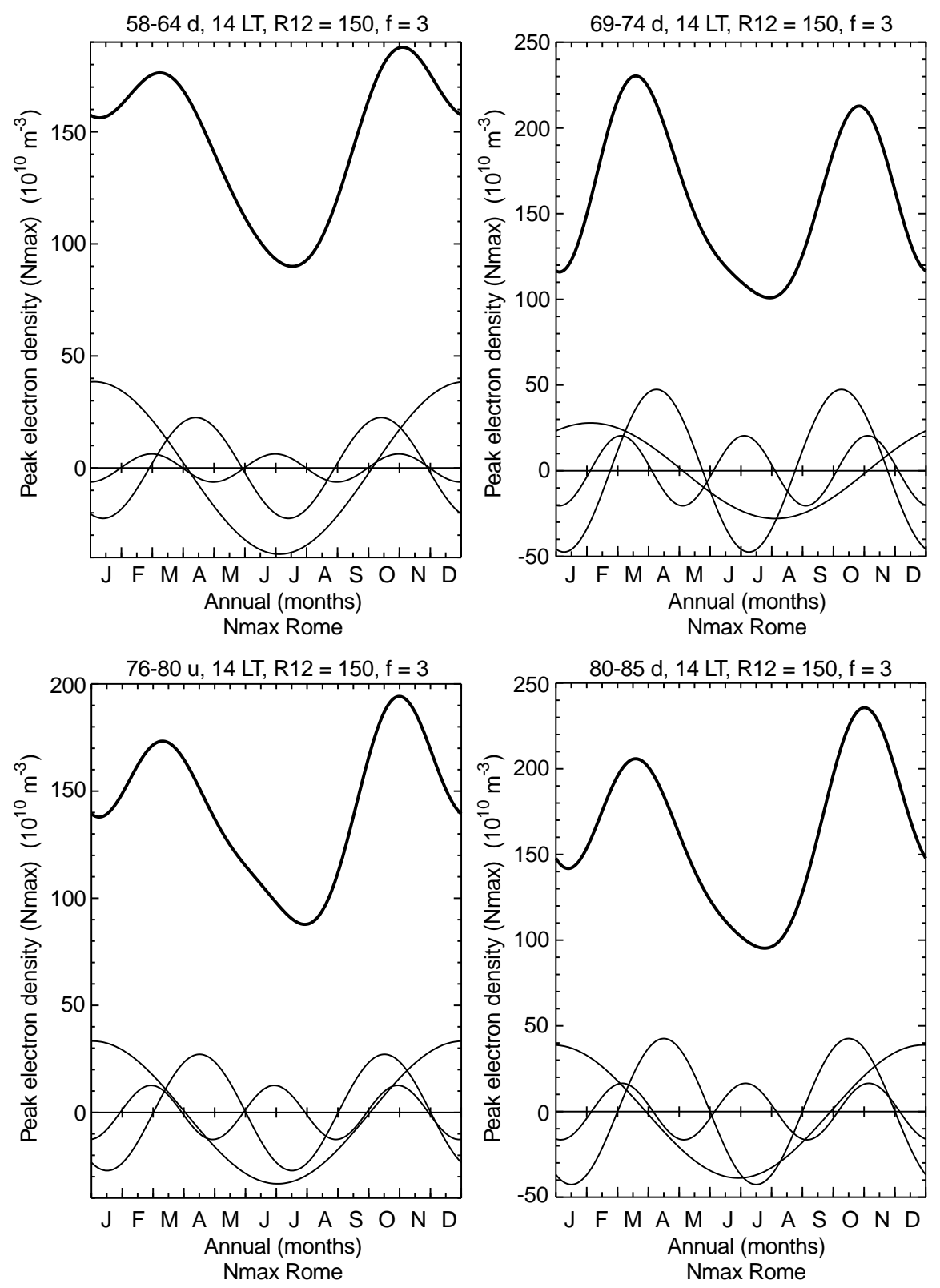

Fig. 7. Annual variation of peak electron density $\left(N_{\max }\right)$ from four Fourier components (mean, 1 year, 1/2 year, 4 months). High solar activity $\left(R_{12}=150\right.$, from regression), solar cycle 19 falling part (top, left-hand side), 20 falling part (top, right-hand side), 21 rising part (bottom, left-hand side) and 21 falling part (bottom, right-hand side). The 1-year, 1/2-year, 4-month components are shown separately (thin lines) 


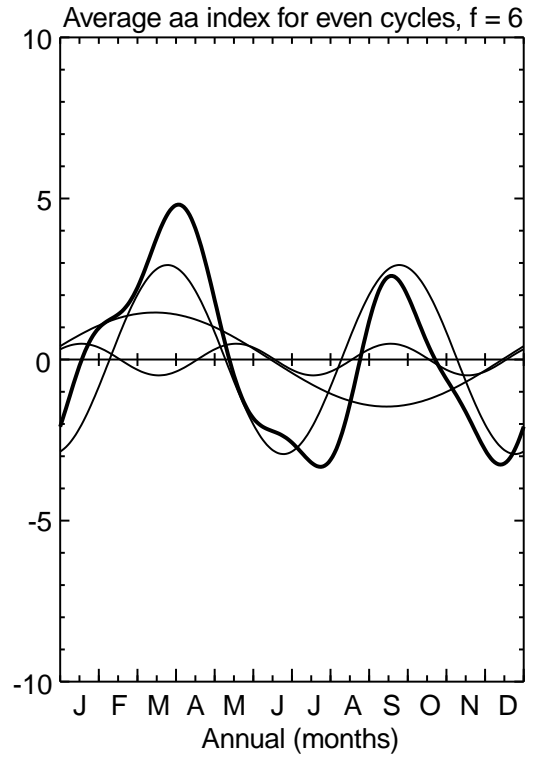

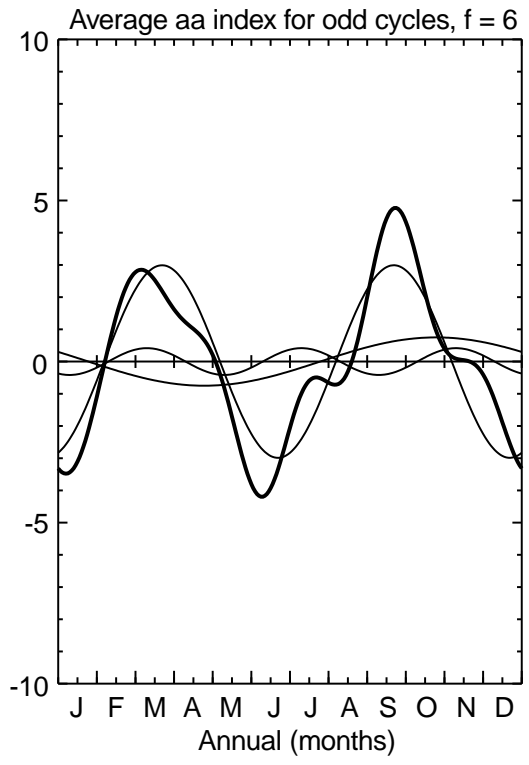

Fig. 8. Annual deviation from mean of the $a a$ index averaged over cycles 18, 20, 22 (left) and 19, 21, 23 (right). The 1-, 1/2- and 1/3-year components are also shown (thin lines) behaviour was demonstrated for these parts of the solar cycles from 1873 to 1980 which have a well-developed solar dipole polarity (Triskova, 1989).

An analysis of monthly medians of $a a$ from solar cycles $18-23$ using essentially the Fourier method was applied to the TEC, and $N_{\max }$ data shows that the phase of the annual component might be responsible for the 22-year period in geomagnetic activity (Fig. 8).

This $a a$-index behaviour might provide a basis for explanations of the double sunspot cycle in the total electron of the ionosphere, because the geomagnetic activity certainly influences the ionospheric behaviour.

Qualitatively the relation between magnetic activity (described by a magnetic-activity indicator) and F-layer ionization can be explained by means of varying energy input into the high-latitude thermosphere (Joule heating and other particle precipitation effects). Quantitative explanations are a difficult task; for instance, the magnetic activity indicators available for long-term investigations have no direct relation to particle precipitation nor to current systems.

\section{References}

Apostolov, E. M., and L. F. Alberca, foF 2 hysteresis variations and the semi-annual geomagnetic wave. J. Atmos. Terr. Phys, 57, 755-757, 1995.

Baranyi, T., and A. Ludmány, Semi-annual fluctuation and efficiency factors in sun-weather relations, J. Geophys. Res., 97, 14923-14928, 1992.

Baranyi, T., and A. Ludmány, Role of the solar main magnetic dipole field in the solar-tropospheric relations. Part I. Semiannual fluctuations in Europe, Ann. Geophysicae, 13, 427-436, 1995a.

Baranyi, T., and A. Ludmány, Role of the solar main magnetic dipole field in the solar-tropospheric relations. Part II. Dependence on the types of solar sources, Ann. Geophysicae, 13, 886892, 1995b.

Bartels, J., Discussion of time-variations of geomagnetic activity, indices Kp and Ap, 1932-1961, Ann. Géophys., 19, 1-20, 1963.
Chernosky, E. J., Double sunspot-cycle variation in terrestrial magnetic activity 1884-1963, J. Geophys. Res., 71, 965-974, 1966.

Cortie, A. L., Sunspots and terrestrial magnetic phenomena, 1898 1911, Mon. Not. R. Astron. Soc., 73, 52-60, 1912.

da Rosa, A. V., H. Waldman, and J. Bendito, Response of the ionospheric electron content to fluctuations in solar activity, $J$. Atmos. Terr. Phys., 35, 1429-1442, 1973.

Ebel, A., Temporal and spatial changes of the electron content of the ionosphere, J. Atmos. Terr. Phys., 32, 1649-1660, 1970.

Ebel, A., Der ionosphärische Elektroneninhalt und seine weltweiten langperiodischen Änderungen, Mitt. Inst. Geophys. Meteorol. Univ. Köln, 17, 1971.

Feichter, E., and R. Leitinger, Long-term studies of ionospheric electron content, Wiss. Ber. 1/93, Institut für Meteorologie und Geophysik, Universität Graz, 1993.

Feichter, E., R. Leitinger, and G. K. Hartmann, Untersuchungen über die Halbjahres- und die Jahreswelle in F-Schicht-Parametern, Kleinheubacher Ber., 31, 249-258, 1988.

Feichter, E., R. Leitinger, and G. K. Hartmann, Vergleich von Ionosphärenparametern aus zwei Sonnenfleckenzyklen, Kleinheubacher Ber, 33, 93-102, 1990.

Feichter, E., R. Leitinger, and G. K. Hartmann, Die Halbjahresperiode in der Thermosphäre und in der Ionosphäre - ein Vergleich, Kleinheubacher Ber, 34, 207-214, 1991.

Fraser-Smith, A. C., Spectrum of the geomagnetic activity index Ap, J. Geophys. Res., 77, 4209-4220, 1972.

Garriot, O. K., A. V. da Rosa, and W. J. Ross. Electron content obtained from Faraday rotation and phase path length variations. J. atmos. terr. Phys. 32, 705-727, 1970

Galdón, E., and L. F. Alberca, Influence of solar activity on the total electron content of the ionosphere over Tortosa, Radio Sci., 3, 913-915, 1970.

Huang,Y. -N., Solar cycle and seasonal variations of the solar and lunar daily variations of total electron content at Lunping, $J$. Geophys. Res., 84, 6595-6601, 1979.

Leitinger, R., and E. Putz, Die Auswertung von Differenz-DopplerMessungen an den Signalen von Navigationssatelliten, Techn Bericht, Universität Graz, 1978.

Leitinger, R., G. Schmidt, and A. Tauriainen, An evaluation method combining the differential Doppler measurements from two stations that enables the calculation of the electron content of the ionosphere, J. Geophys, 41, 201-213, 1975.

Mayaud, P. N., The $a a$ indices: a 100-year series characterizing the magnetic activity, J. Geophys. Res., 77, 6870, 1972. 
E. Feichter, R. Leitinger: A 22-year cycle in the F layer ionization of the ionosphere

Meyer, J., A 12-month wave in geomagnetic activity, J. Geophys. Res., 77, 3566-3572, 1972.

Münch, J. W., The annual variation of the earth-magnetic activity according to the character figures Ci, Planet. Space Sci., 20, 225-231, 1972.

Priester, W., and D. Cattani, On the semiannual variation of geomagnetic activity and its relation to the solar corpuscular radiation, J. Atmos. Sci., 19, 121-126, 1962.

Prölss, G. W., Storm-induced changes in the thermospheric composition at middle latitudes, J. Planet. Space Sci., 35, 807-811, 1987.

Prölss, G. W., and M. Roemer, Thermospheric storms, Adv. Space Res., 7, (10)223-(10)235, 1987.

Putz, E., N. Jakowski, and P. Spalla, Statistische Untersuchungen von Ionosphärenstürmen und erste Modellrechnungen, Kleinheubacher Ber., 33, 121-129, 1990.

Russell, C. T., and R. L. Mc Pherron, Semi-annual variation of geomagnetic activity, J. Geophys. Res., 78, 92-108, 1973.
Taeusch, D. R., G. R. Carignan, and C. A. Reber, Neutral composition variations above $400 \mathrm{~km}$ during a magnetic storm, J. Geophys. Res., 76, 8318-8325, 1971.

Titheridge, J. E. and M. J. Buonsanto, A comparison of northern and southern hemisphere TEC storm behaviour, J. Atmos. Terr. Phys., 50, 763-780, 1988.

Titheridge, J. E., R. Leitinger, and E. Feichter, Comparison of the long-term behaviour of the F-layer of the ionosphere, northern versus southern hemisphere, Kleinheubacher Ber., 39, 749-755, 1996.

Triskova, L., The vernal-autumnal asymmetry in the seasonal variation of the magnetic activity, J. Atmos. Terr. Phys., 51, 111-118, 1989.

Yuen, P. C., and T. H. Roelofs, Seasonal variations in ionospheric total electron content, J. Atmos. Terr. Phys., 29, 321-326, 1967. 